\title{
Assessment of genetic diversity and fingerprinting of strawberry genotypes using inter simple sequence repeat marker
}

\begin{abstract}
In this study, the ability Inter Simple Sequence Repeat markers (ISSR) were used to identify molecular relationships among wild, local and commercial genotypes of strawberry. Twelve out of the 25 tested primers produced clear and reproducible fragments with high value of polymorphism $(96.5 \%)$. The number of bands per primer ranged from 6 to 18 with an average of 13.16 bands. Clustering based on Jaccard's similarity coefficient divided the genotypes into five groups and separated wild accessions from others. The highest genetic distance was between Kaleybar and Pahnekola sari accessions with 0.31 similarity index that is promising to obtain hybrids with greater heterotic effect and segregation. The results indicated that there are high value of divergence between the genotypes and clearly demonstrate that ISSR markers can be used in a genetic diversity studying as well as in genotypic identification of strawberries. The results of the study can be use for further analysis, including fingerprinting, preservation of genetic resources, parental selection and hybrid/cross-breeding programs.
\end{abstract}

Keywords: fingerprinting, genetic diversity, genetic relatedness, issr marker, strawberry, wild species
Volume 2 Issue 5 - 2018

\author{
Behzad Shahin Kaleybar, Ghorban Ali \\ Nematzadeh, Yosef Ghasemi, Seyyed \\ Hamidreza, Hashemi Petroudi \\ Genetics and Agricultural Biotechnology Institute of Tabarestan, \\ Sari Agricultural Sciences and Natural Resources University, Iran

\begin{abstract}
Correspondence: Behzad Shahin Kaleybar, Genetics and Agricultural Biotechnology Institute of Tabarestan, Sari

Agricultural Sciences and Natural Resources University, Iran, Tel
\end{abstract} \\ +989141290839, Email shahan.bio65@gmail.com
}

Received: August 17,2017| Published: October II, 2018

\section{Abbreviations}

ISSR, inter simple sequence repeat markers; RAPD, random amplified polymorphic dna; ROS, reactive oxygen species; SSR, simple sequence repeats or microsatellites; AFLP, amplified fragment length polymorphism; PIC, polymorphic information content; UPGMA, unweighted pair group method with arithmetic mean

\section{Introduction}

Ability of a plant species to respond adaptively to environmental challenges depends on its genetic diversity. ${ }^{1}$ Strawberry is an economically and commercially important horticultural crop with rich source of bioactive compounds that are beneficial to human health. ${ }^{2}$ It has been reported that strawberry fruits, because of its high levels of vitamin $\mathrm{C}$ and $\mathrm{K}$, folate, phenolic compounds and flavonoids, retards age-related effects on memory. ${ }^{3}$ Fruits of this horticultural crop are widely consumed fresh or in processed forms, such as jams, juices, and jellies. Strawberry fruits also has shown antioxidant and anti-cancer properties by inhibiting production of Reactive Oxygen Species (ROS) and carcinogens reduction. ${ }^{4-6}$ The diversity and high properties value of its compounds make strawberry a very attractive fruit for studying. Wild strawberry species as genetic resources are valued by breeders to produce new varieties with novel traits that are more productive, more nutritious, more market-friendly and more resistant to biotic (viruses, fungi, bacteria, weeds, insects and pests) and abiotic (drought, salinity, cold, heat) stresses. There are several systems such as morphological, chemical, and biochemical markers for evaluating diversity levels in plants. But these systems of classification are influenced by factors like temperature, humidity, light and/or plants ages which can modify results of classification.
While, DNA-based marker systems provide a reliable and powerful tools for assessing differences between organisms with simultaneous elimination of the other systems constraints and are increasingly used in breeding programs and germplasm management of many horticultural crops. Several PCR (polymerase chain reaction)based DNA marker systems including RAPD (random amplified polymorphic DNA), AFLP (amplified fragment length polymorphism) and SSRs (simple sequence repeats or microsatellites) are available for genetic assessment, ${ }^{7}$ but each of the methods have some limitations: low primer annealing temperature and reproducibility for RAPD, requirement for prior sequence information from flanking regions to develop primers for SSR and high experiment costs for AFLP. ISSR marker is a cheap, fast and simple genotyping technique based DNA that requires small amounts of DNA template. ${ }^{8}$ This marker is more reliable than RAPD because of longer length of primers and high annealing temperature and ISSR does not requires any prior sequence information. ISSR marker uses a single primer targeting microsatellite motifs that generates abundant polymorphic bands with a reliable and reproducible banding patterns in many systems. ${ }^{7,9,10}$ ISSR marker has been used successfully to assess genetic variation in a vast range of plants and horticultural crops including blueberry, ${ }^{11}$ lingo berry, ${ }^{12}$ citrus, ${ }^{13}$ potato, ${ }^{14}$ Oryza ${ }^{15}$ and described as a powerful technique to assess genetic diversity to detect similarities between and within species levels. It is well know that availability and deep knowledge of genetic diversity of any given crop will enhance extent of any improvements. ${ }^{16}$ Strawberry belongs to Rosaceae family, which has approximately 3000 members, ${ }^{17}$ Fragaria genera and six species all iedentifies as straswery. Strawberry has different size, color, taste, form, season of ripening, level of fertility and resistance to disease. ${ }^{18}$ One of the most important habitats for wild strawberries genotypes 
in Iran is northern strip, but there are little information on their genetic diversity and molecular relationships. The aim of this study was to evaluate the ISSR markers ability to differentiate strawberry genotypes, fingerprinting some Iranian varieties and determine their molecular relationships. This study is the first report to evaluate ISSR maker to determine the genetic diversity among wild north strip accessions and local varieties of Iranian strawberry genotypes and commercial cultivars. The results can be used to further studies like genetic diversity preservation, breeding programs and genetic or genomic studies.

\section{Materials and methods}

\section{Plant materials and genomic DNA isolation}

In this study sixteen genotypes of strawberry including 9 wild accessions, 4 local varieties and 3 commercial cultivars were used to genetic relationships analysis. The local varieties were (Dalndi, Kordestan, Atabaki and Gilasi), commercial cultivars were (Camarosa, Diamante and Selva) and wild accessions collected from several region of Iran including pasand behshahr, Gorgan, pahnekola Sari, Kaleybar, Ramsar, Lahijan, hezarjarib, savadkoh and zirab (Figure 1). In order to DNA extraction, the seeds of the genotypes were removed from the fruits and cultured in greenhouse in a controlled condition (temperature, $29^{\circ} \mathrm{C}$ day and $27^{\circ} \mathrm{C}$ night; relative humidity, $60 \%$ day and $75 \%$ night; $16 \mathrm{~h}$ illumination per day). After 50 days young leaves were collected from actively grown shoots, immediately frozen in liquid nitrogen and then placed at $-80^{\circ} \mathrm{C}$ until DNA extraction. Genomic DNA was extracted using DNeasy Plant Mini Kit (QIAGEN, Germany) from approximately $0.1 \mathrm{~g}$ of leaf material powdered by mortar and pestle according to manufacturer's instructions. Quantity and quality of isolated DNA was determined by $0.7 \%$ agarose gel electrophoresis using known amounts of diluted uncut lambda DNA as standard and spectrophotometer analysis. The ratio of the absorbance at A260/A280 nm was used for measuring extracted DNA Purity and the samples with purity ratio between 1.8 2 were selected for subsequent applications and analyzing by ISSR marker.

\section{ISSR amplification}

Twenty-five ISSR primers were screened to determine their ability for detecting polymorphism among genotypes. Optimization of Polymerase chain reaction (PCR) amplifications were accomplished by changing concentrations of $\mathrm{MgCl}_{2}$, genomic DNA and annealing temperature. Finally the PCR reactions were performed in a volume of $20 \mu \mathrm{l}$ reaction mixture containing $60 \mathrm{ng}$ of template DNA, $0.6 \mathrm{mM}$ of each dNTPs, 1XTaq buffer PCR $(10 \mathrm{mM}$ Tris- $\mathrm{HCl}, 50 \mathrm{mM} \mathrm{KCl}$ ( $\mathrm{pH}$ 8.8) and 0.08 Nonidet $\mathrm{P} 40$ ), $2 \mathrm{mM} \mathrm{MgCl}_{2}, 1 \mathrm{U}$ of Taq DNA polymerase and $0.4 \mu \mathrm{M}$ of the ISSR primer. To reduce background amplification, $2 \%(\mathrm{v} / \mathrm{v})$ formamide was added to the reaction mixture. ${ }^{19}$ Amplification reactions were carried out using ABI Applied Biosystems thermal cycler with an initial denaturation step of $5 \mathrm{~min}$ at $95^{\circ} \mathrm{C}$, followed by 35 cycles; each cycle included $94^{\circ} \mathrm{C}$ for $40 \mathrm{~s}, 55^{\circ} \mathrm{C}$ for $1 \mathrm{~min}, 72^{\circ} \mathrm{C}$ for $2 \mathrm{~min}$ and a final extension step at $72^{\circ} \mathrm{C}$ for $7 \mathrm{~min}$. To test DNA contamination of the reagents a reaction, containing all PCR components except DNA (negative control) was used in each experiment. PCR amplified fragments were separated on $2.5 \%$ agarose gels by electrophoresis at $90 \mathrm{~V}$ in $0.5 \times \mathrm{TBE}$ (Tris / Boric Acid / EDTA) buffer. Gels were stained with ethidium bromide ${ }^{20}$ and imaged in Doc-Print VX5 (VIBER LOURMAT) gel documentation system.

\section{Data analysis}

ISSR reproducible fragments were scored as presence (1) or absence (0) for each of the possible band. Since ISSR is a dominant marker, the presence of a band was interpreted as either a heterozygote or dominant homozygote and the absence of a band as recessive homozygote. The data matrix structure was assembled by binomial $(0 / 1)$ data and used as input data for further analysis using NTSYS version 2.02 software program. ${ }^{21}$ Cophenetic matrices were created to test whether clusters in the dendrogram agreed with information from the similarity matrix. Similarity for ISSR data was computed using the Jaccard's similarity index and cluster diagrams were generated with the un-weighted pair group method using arithmetic averages (UPGMA) algorithm. The resulting clusters were expressed as dendrogram.
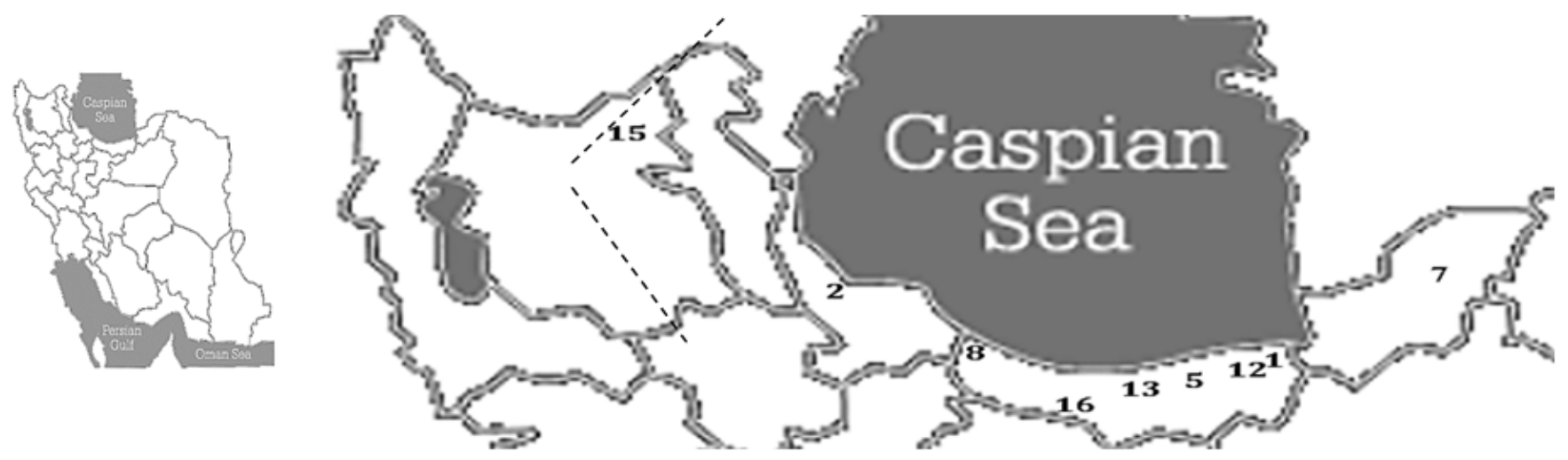

Figure I Collection sites of strawberry accessions from northern strip of Iran. pasand behshahr (I), Gorgan (7), pahnekola Sari (5), Kaleybar (I5), Ramsar (8), Lahijan (2), hezarjarib (I2), savadkoh (13) and zirab (16). 


\section{Results and discussion}

Initially to screen the best primers based on their ability to amplify DNA bands we used 25 ISSR primers that twelve out of which produced clear and reproducible fragments with multiband patterns and were considered as informative and polymorphic primers for further analysis that has been mentioned in Table 1. Within the selected primers there were ten di-nucleotide repeat and two tri-nucleotide repeat primers with 3' anchors, remaining primers produced faint or no distinct bands on gel. For example the amplified bands by primer ISSR-2 has been shown in Figure 2. The primers used differed in size of amplified products between 190-2350 bp (Table 1) and no band was detected in any negative control amplifications. The primer \#ISSR-19 exhibited the highest size variation of amplified products (300-2350bp) and the smallest one was observed for primer \#ISSR-1 (190-840bp). Primer \#ISSR-1 also produced the highest number of loci (18 loci) and the lowest one was amplified by primer ISSR-5 (6 loci) and the average bands per primer was 13.16. In total 155 loci were visualized with polymorphism range between 80 to $100 \%$ with an average of $96.5 \%$ that representing higher value of divergence between the genotypes and a high efficiency of the used primers to distinguish between the strawberry genotypes that the haracteristics of the primers have been shown in Table 2. Polymorphic Information Content (PIC) is a parameter that refers to value of a marker for detecting degree of polymorphism within a population and depends on number of detectable alleles and the distribution of their frequency. ${ }^{22}$ Analysis of the data showed that the PIC value varied from 0.18 to 0.31 , with an average of 0.24 . Primer \#ISSR-13 by showing the highest
PIC value ( $\mathrm{PIC}=0.31$ ) (Table 3 ) was recognized as appropriate and discriminating primer to estimate genetic similarity and diversity of the strawberry genotypes and used as a good primer for fingerprinting of the cltivars that its sequence has been presented in Figure 2 .

\section{Genetic relationships}

The diversity data obtained from similarity analysis were varied between 0.31 to 0.70 with an average of 0.43 The high genetic divergence found may have been due to a highly heterozygote genetic structure among the strawberry genotypes because of their different origins and ploidy levels. The highest similarity index was between Camarosa (10) and Diamant (11) cultivars with value of $70 \%$. These cultivars came from the same breeding programs and were developed at the University of California and may share ancestors. Morales et al. ${ }^{23}$ in studying of genetic diversity among strawberry cultivars using ISSR and RAPD markers, have reported high similarity index between Camarosa and Diamant cultivars with value of $67 \%$ similarity. The lowest similarity index was between pahnekola sari (5) and Kaleybar (15) accessions with value of 31\% similarity. This degree of dissimilarity may be cause of a diverse genetic background of Kaleybar accession because of its geographical distance (Figure 3). In plant breeding programs the genotypes that have the highest genetic distance and high means of performance for the target traits are used as parents to crosses with adapted varieties for obtaining hybrids with greater heterotic effect and segregation. ${ }^{24-26}$ In this sense, it could be inferred that crosses involving the Kaleybar genotype because of its good characteristics such as high resistance to cold stress and lowest similarity $(60 \%)$ to the other genotypes is the most interesting.

Table I The list and features of ISSR primers used in this

\begin{tabular}{|c|c|c|c|c|c|c|c|}
\hline Primer & $\begin{array}{l}\text { Sequence } \\
\left(5^{\prime} \text { to } 3^{\prime}\right)\end{array}$ & $\begin{array}{l}\text { Annealing } \\
\text { temperature }\left({ }^{\circ} \mathrm{C}\right)\end{array}$ & $\begin{array}{l}\text { Fragment size } \\
\text { length }\end{array}$ & $\begin{array}{l}\text { Total no. of } \\
\text { bands }\end{array}$ & $\begin{array}{l}\text { No. of Polymorphic } \\
\text { bands }\end{array}$ & $\begin{array}{l}\text { Polymorphism } \\
(\%)\end{array}$ & PIC \\
\hline ISSR-I & $(\mathrm{GA})_{9} \mathrm{~A}$ & 55 & $190-840$ & 18 & 18 & 100 & 0.23 \\
\hline ISSR-2 & $(\mathrm{GA}){ }_{9} \mathrm{C}$ & 57 & $250-1500$ & II & 11 & 100 & 0.27 \\
\hline ISSR-5 & $(\mathrm{GT}){ }_{9} \mathrm{C}$ & 57 & $470-1300$ & 6 & 6 & 100 & 0.28 \\
\hline ISSR-8 & $(\mathrm{CT})_{8} \mathrm{G}$ & 51 & $320-1620$ & 14 & 14 & 100 & 0.27 \\
\hline ISSR-9 & $(\mathrm{AG})_{8} \mathrm{C}$ & 51 & $265-1200$ & 15 & 14 & 93 & 0.19 \\
\hline ISSR-II & $(\mathrm{GA})_{8} \mathrm{C}$ & 51 & $300-1500$ & 16 & 16 & 100 & 0.24 \\
\hline ISSR-I3 & $(\mathrm{TC})_{8} \mathrm{C}$ & 51 & $570-1670$ & 8 & 7 & 80 & 0.31 \\
\hline ISSR-I4 & $(\mathrm{TC})_{8} \mathrm{G}$ & 51 & $560-1580$ & 14 & 14 & 100 & 0.18 \\
\hline ISSR-I6 & $(\mathrm{TG})_{8} \mathrm{~A}$ & 50 & $450-1840$ & 13 & 13 & 100 & 0.21 \\
\hline ISSR-I7 & $(\mathrm{AC})_{8} \mathrm{C}$ & 51 & $485-1820$ & 15 & 15 & 100 & 0.2 \\
\hline ISSR-I8 & $(\mathrm{ATC})_{6} \mathrm{~T}$ & 49 & $200-1450$ & 14 & 14 & 100 & 0.24 \\
\hline
\end{tabular}

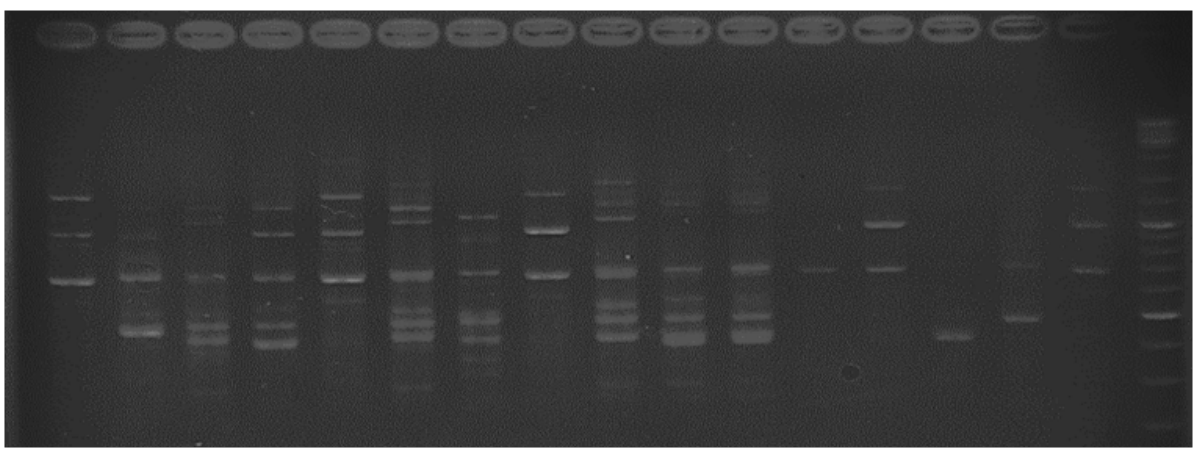

Figure 2 The amplification profile of strawberry genotypes using primer 2 and separated in $2.5 \%$ agarose gel. 


\section{Cluster analysis}

In order to distinguish the best methods for clustering and similarity coefficient calculation, the cophenetic correlation, a measure of the correlation between the similarity represented on the dendrogram and the actual degree of similarity, was calculated for each method combination (Table 2). The UPGMA clustering method based on Jaccard's similarity coefficient, exhibited the highest value of cophenetic correlation ( $\mathrm{r}=0.88)$, Therefore the dendrogram constructed based on this method was used for representing genetic diversity of genotypes (Figure 4). Multivariate statistics such as cluster and principal components analysis play a principle role in investigation genetic distance diversity and evolution of plants. Assessment of Genetic diversity is important not only for efficient management and conservation of germplasm resources but also is essential for crop improvement. Cluster analysis based on the genetic similarity divided the strawberry genotypes into five groups at the cutoff level of $43 \%$ similarity. Group I contains 6 accessions out of 9 wild accession (Pasand behshahr, Pahnehkola sari, Ramsar, Hezarjarib, Savadkoh, Zirab) that indicates the ability of the ISSR marker for strawberry genotypes genetic diversity studying. Group II contains all commercial genotypes (i.e. Camarosa, Diamante and Selva) and local varieties (Dalandi, Kordestan, Atabaki and Gilasi). It should be noted that there are no detailed reports on genetic backgrounds and origins of local varieties that are grown in Iran. The dendrogram and similarity data analysis exhibited a close genetic background of Iranian local varieties with commercial cultivars especially with Camarosa. These results raise the possibility of a common ancestor among them. Groups III, IV and V each contain only one wild accession that was coherent with their origins. Similarity data analysis showed a high level of genetic distances among the three Iran wild accessions of northern strip (Groups III, IV and V) with other ones that is indicative of their different genetic backgrounds. It may be due to geographical distance of the genotypes because they were collected from different provinces. To show multiple dimensions distribution of the genotypes and better explaining genetic variation in a scatter-plot, principal coordinate analysis was performed on the basis of Jaccard similarities. The first, second and third components represented $12 \%, 10 \%$ and $9 \%$ of the total variance respectively and the first 10 coordinates explained $78 \%$ of total variation that are indicative of appropriate sampling of primers and scattering them over different parts of the genome.

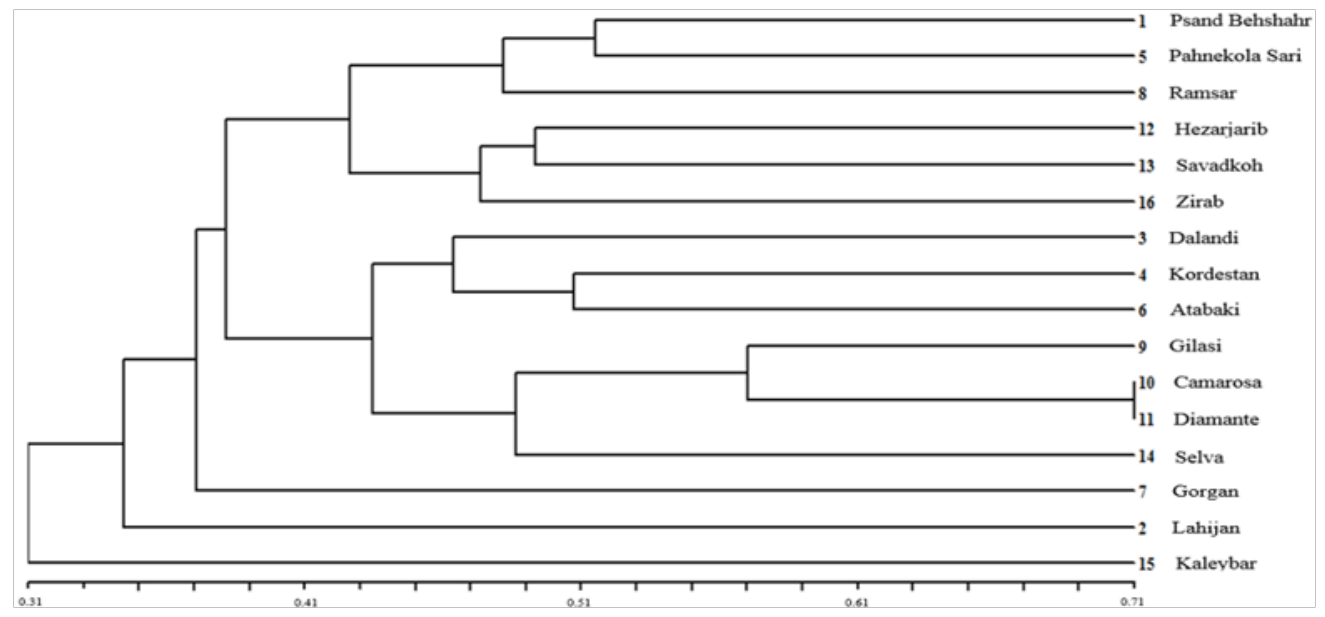

Figure 3 Constructed dendrogram based on Jaccard's similarity coefficient and UPGMA algorithm to show the genetic relationships among 16 genotypes of Strawberry by ISSR marker.

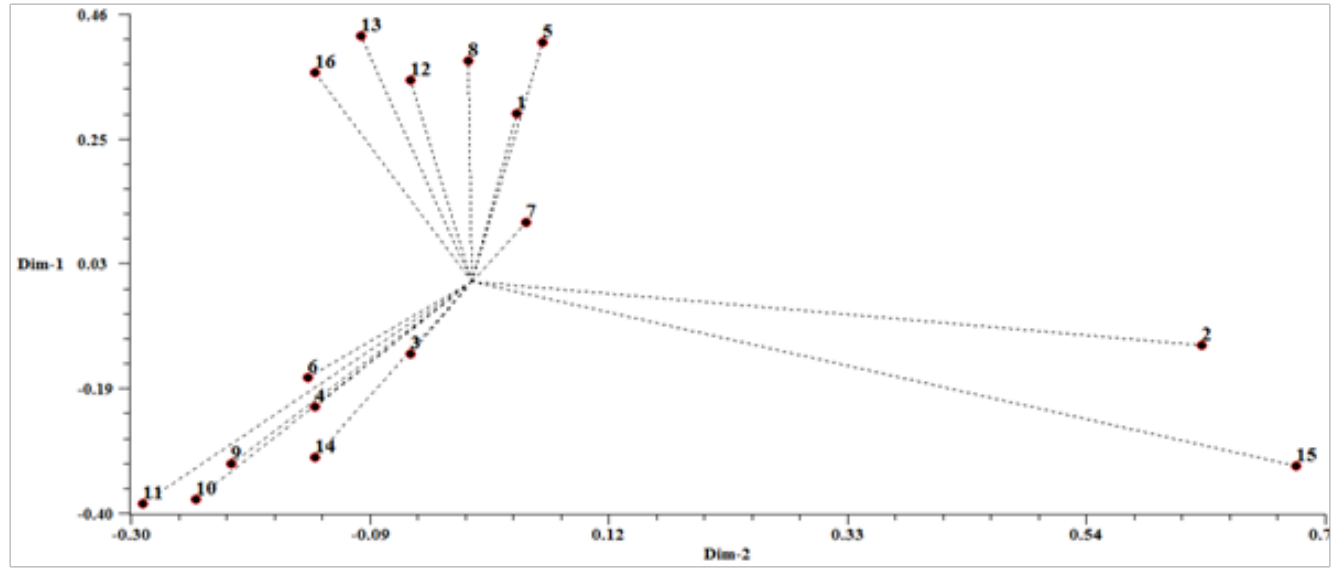

Figure 4 Principal coordinates analysis of 16 strawberry genotypes based on ISSR marker. 
Table 2 Calculated Cophenetic correlation for each method combination

\begin{tabular}{llll}
\hline & Dice's similarity & Jaccard's similarity & SM's similarity \\
\hline UPGMA & 0.86895 & 0.8858 & 0.67998 \\
UPGMC & 0.86895 & 0.53729 & 0.29065 \\
COMPLETE & 0.80569 & 0.83188 & 0.66416 \\
SINGLE & $0.8421 \mathrm{I}$ & $0.8558 \mathrm{I}$ & 0.6909 \\
\hline
\end{tabular}

Table 3 Identification of four cultivars on the basis of the presence (+) or absence (-) of ISSR markers

\begin{tabular}{|c|c|c|c|c|c|c|c|c|c|c|c|c|c|}
\hline \multirow{3}{*}{ Cultivers } & \multicolumn{13}{|c|}{ ISSR primers(bp) } \\
\hline & \multicolumn{3}{|l|}{ ISSR-2 } & \multicolumn{3}{|c|}{ ISSR-9 } & \multicolumn{2}{|c|}{ ISSR-I 3} & \multicolumn{2}{|l|}{ ISSR-I 6} & \multicolumn{3}{|l|}{ ISSR-I 8} \\
\hline & 1000 bp & I I50 bp & $\begin{array}{l}400 \\
\text { bp }\end{array}$ & $\begin{array}{l}500 \\
\text { bp }\end{array}$ & $\begin{array}{l}820 \\
\text { bp }\end{array}$ & $\begin{array}{l}410 \\
\text { bp }\end{array}$ & $\begin{array}{l}1000 \\
\text { bp }\end{array}$ & I 350 bp & 700 bp & $950 \mathrm{bp}$ & $250 \mathrm{bp}$ & 1200 bp & $800 \mathrm{bp}$ \\
\hline Dalandi & - & + & - & - & - & - & - & + & + & + & + & - & - \\
\hline Kordestan & - & - & - & + & - & + & + & - & - & - & + & - & - \\
\hline Atabaki & + & + & + & + & + & + & - & + & - & - & - & - & + \\
\hline Gilasi & - & + & - & - & - & + & + & - & + & - & - & + & + \\
\hline
\end{tabular}

\section{Acknowledgements}

None.

\section{Conflict of interest}

Authors declare that there is no conflict of interest.

\section{References}

1. Ayala FJ, Kiger JA. Modern genetics. USA: Menlo Park; 1985;13(2):87.

2. Giampieri F, Tulipani S, Alvarez Suarez JM, et al. The strawberry: Composition, nutritional quality, and impact on human health. Nutrition. 2012;28(1):9-19.

3. Bickford PC, Gould T, Briederick L, et al. Antioxidant-rich diets improve cerebellar physiology and motor learning in aged rats. Brain Res. 2000;866:211-217.

4. Wang SY, Jiao H. Scavenging capacity of berry crops on superoxide radicals, hydrogen peroxide, hydroxyl radicals, and singlet oxygen. $J$ Agric Food Chem. 2000;48(11):5677-5684.

5. Chung MJ, Lee SH, Sung NJ. Inhibitory effects of whole strawberries, garlic juice or kale juice on endogenous formation of $\mathrm{N}$-nitrosodimethylenamine in humans. Cancer Lett. 2002;182(1):1-10.

6. Kresty LA, Morse MA, Morgan C, et al. Chemoprevention of esophageal tumorigenesis by dietary administration of lyophilized black raspberries. Cancer Res. 2001;61(16):6112-6119.

7. Pradeep Reddy M, Sarla N, Siddiq EA. Inter simple sequence repeat (ISSR) polymorphism and its application in plant breeding. Euphytica. 2002;128(1):9-17.

8. Nagaoka T, Ogihara Y. Applicability of inter-simple sequence repeat polymorphisms in wheat for use as DNA markers in comparison to RFLP and RAPD markers. Theor Appl Genet. 1997;94(5):597-602.

9. Matthews D, McNicoll J, Harding K, et al. 5-anchored simple sequence repeat primers are useful for analysing potato somatic hybrids. Plant Cell Reports. 1999;19:210-212.
10. Liu B, Wendel JF. Intersimple sequence repeat (ISSR) polymorphisms as a genetic marker system in cotton. Molecular Ecol. 2001;1(3):205-208.

11. Debnath SC, Elodie R. ISSR, anthocyanin content and antioxidant activity analyses to characterize strawberry genotypes. J Applied Horticulture. 2009;11(2):83-89.

12. Debnath SC. Inter simple sequence repeat (ISSR) to assess genetic diversity within a collection of wild lingonberry (Vaccinium vitis-idaea L.) clones. Canad J Plant Sci. 2007;87(2):337-344.

13. Fang DQ, Roose ML. Identification of closely related citrus cultivars with inter-simple sequence repeats markers. Theor Appl Genet. 1997;95(3):408-417.

14. Prevost A, Wilkinson MJ. A new system of comparing PCR primers applied to ISSR fingerprinting of potato cultivars. Theor Appl Genet. 1999;98(1):107-112.

15. Qian W, Ge S, Hong DY. Genetic variation within and among populations of a wild rice Oryza granulata from China detected by RAPD and ISSR markers. Theor Appl Genet. 2001;102(2-3):440-449.

16. Diamant J, Capocas F, Balducci F. Increasing Strawberry Fruit Sensorial and Nutritional Quality Using Wild and Cultivated Germplasm. PLoS ONE. 2012;7(10):e46470.

17. Baumgardt JP. How to identify flowering plant families: A Practical Guide for Horticulturists and Plant Lovers. Portland: 1982;230-1.

18. Biswas MK, Dutt M, Roy UK, et al. Development and evaluation of in vitro somaclonal variation in strawberry for improved horticultural traits. Scientia Horticulturae. 2009;122: 409-416.

19. Pharmawati M, Yan G, Finnegan PM. Molecular Variation and Fingerprinting of Leucadendron Cultivars (Proteaceae) by ISSR Markers. Ann Bot. 2005;95(7):1163-1170.

20. Sambrook J, Fritsch EF, Maniatis T. Molecular Cloning: A Laboratory Manual. $2^{\text {nd }}$ Edition. New York: Cold Spring Harbor; 1989.

21. Rohlf FJ. NTSYS-pc 2.0 Numerical Taxonomy and variate Analysis System. Department of Ecology and Evolution. State University of New York: Exeter Software; 1998. 
22. Ramamoorthi J, Thilagam K, Sivaselvam SN. Genetic characterization of Barbari goats using microsatellite markers. J Vet Sci. 2009;10(1):73-76.

23. Morales RGF, Resende JTV, Faria V, et al. Genetic similarity among strawberry cultivars assessed by RAPD and ISSR markers. Scientia Agricola. 2011;68(6):665-670.

24. Moghaddam M, Mohammadi Shoti A, Aghaei Sarbarzeh M. Introduction to Multivariate Statistical Methods. Iran: Science Vanguard; 1994
25. Cruz CD, Carneiro CS. Biometric models applied to genetic improvement. Federal University of Viçosa; 2003. 390 p.

26. Benin G, Carvalho FIF, Oliveira AC, et al. Comparação entre medidas de dissimilaridade e estatística multivariadas como critérios no direcionamento de hibridação de aveia. Ciência Rural. 2003;33: 657-662. 